\title{
PHYLOGENETIC ANALYSIS OF BOVINE EPHEMERAL FEVER VIRUS ISOLATED FROM EGYPTIAN OUTBREAKSIN (2013 TO 2016)
}

Samy Kasem ${ }^{1}$, Noura Alkhalefa ${ }^{1}$, Asmaa Magouz ${ }^{1}$, BasmaEbrahem ${ }^{1}$, Mohamed Khodier ${ }^{2}$, Walied Abdo ${ }^{3}$ and Abdelrazek Desouky ${ }^{4}$

${ }^{1}$ Department of Virology, Faculty of Veterinary Medicine, Kafrelsheikh University, 33516, El-Geish Street, Kafrelsheikh, Egypt

${ }^{2}$ Veterinary Serum and Vaccine Research Institute, Abbasia, Cairo, Egypt ${ }^{3}$ Department of pathology, Faculty of Veterinary Medicine, Kafrelsheikh University, 33516, El-Geish Street, Kafrelsheikh, Egypt

${ }^{4}$ Department of Parasitology, Faculty of Veterinary Medicine, Kafrelsheikh University, 33516, El-Geish Street, Kafrelsheikh, Egypt

\begin{abstract}
Bovine ephemeral fever(BEF) suspected outbreaks recorded during the summer of (2013 to 2016)in the Delta provinces of Egypt. The aim of this study was the isolation and molecular characterization of BEF viruses detected from these outbreaks, as there is no currently information about BEFV in Egypt. Blood samples were collected from suspected cases andthe virus was isolated intracerebrallyin baby mice then passed to Madin Darby Bovine Kidney (MDBK) andAfrican green monkey kidney (VERO) cell lines. The isolated virus was identified by RT-PCR followed by sequencing of the glycoprotein $(G)$ gene of BEFV isolate.The construction of phylogenetic tree based on genetic relationships of the BEFV isolate derived from Egypt and different countries was performed. The phylogenetic treeshowed that the Egyptian isolate was closely linked to the Israeli and Turkish isolates.
\end{abstract}

Keywords: BEFV, Glycoprotein G gene, RT-PCR, sequencing, Egypt, 


\section{INTRODUCTION}

Bovine ephemeral fever virus (BEFV) is an acute febrile, arthropod-born viral disease of cattle and water buffalo. The disease is clinically manifested by sudden occurrence of fever,lameness, stiffness, and spontaneous recovery within three days. The morbidity may be high but low mortality rate. The disease causes significant economic losses due to low production in dairy herds and drop in condition of prime animals or stock movementdisruption and markets (Hsieh et al., 2005; Walker, 2005). BEF is endemic in tropical and subtropical regions of Africa, Asia, Australia and the Middle East (St. George, 1997; Wang et al., 2001; Venter et al., 2003; Yeruham et al., 2003).

BEF disease is caused by a virus that belongs to the Ephemerovirus, which is a member of the Rhabdoviridae family (Wunner et al., 1995). BEFV has abullet shapewith a linear ssRNA genome ofnegative sense. The virus contains five structural proteins; nucleoprotein $(\mathrm{N})$, surface glycoprotein $(\mathrm{G})$,polymerase associate protein (P), large RNA-dependent RNA polymerase (L), and matrix protein (M) (Walker et al., 1991; Walker et al., 1992). Studies of monoclonal antibody indicated that the $G$ protein is the main protective antigen. (Kongsuwan et al., 1998; Walker et al., 1994). Four antigenic sites (G1, G2, G3 and G4) have been detected on the surface of the G protein (Cybinski et al., 1990; Dhillon et al., 2000).

In Egypt, the disease was first described by Rabagliati, 1924, and several subsequent outbreaks of BEFV had been occurred in summer of 2000, 2001, 2004, 2010 and 2012 (Rabagliati, 1924; Zaghawa et al., 2000; Kasem, 2004; Kawther and Wahid 2011; Kasem et al., 2014). 
To date, there is no information available on the BEFVG genenucleotide sequences isolated in Egypt. In this study, molecular characterization of BEFVG gene by RT-PCR followed by geneticanalysis the nucleotide sequences of the $G$ gene of isolates from the Delta governorates.

\section{MATERIALS AND METHODS}

\section{Sampling:}

A total of 123random samples were collected from clinically BEFsuspected animals from El- Gharbiya governorates. Blood samples were collected in EDTA-containing vacationer tubes from jugular veins of animals from each case for virus isolation. All labeled samples were kept in ice container on the top of ice. The specimens were then transported to the Central Analytic laboratory, Faculty of Veterinary Medicine, Kafrelsheikh University. The Buffy coat from non-clotted blood samples were separated by low speed centrifugation at $3000 \mathrm{rpm}$ for 15 minutes. The interface Buffy coat was transferred by sterile syringe into sterile tube, washed by phosphate buffered saline (PBS) for three times and kept at $-80^{\circ} \mathrm{C}$ till used for the BEFV isolation (Kasem et al., 2014).

\section{Isolation of Bovine Ephemeral Fever Virus:}

African green monkey kidney cell line (VERO) and Madin Darby Bovine Kidney Cell line (MDBK) were kindly supplied by Serum and Vaccine Research Institute, Abbasia, Cairo, Egypt,used for isolation and propagation of BEF virus. The cells were maintained in Eagle's minimal essential medium (E-MEM) supplemented with 5-10\% fetal bovine serum, $100 \mathrm{U} / \mathrm{ml}$ of streptomycin and $100 \mathrm{mg} / \mathrm{ml}$ of penicillin. 
The samples were inoculated intracerebrallyin suckling mice(2-3 days- old). Infected baby mice were kept under observation. Infected mice showed paralysis and stiffness in their hind legs on the second to third day after inoculation and died during 24-36 hours post morbidity. Subsequently, confluent monolayers of cultured cells were inoculated with BEFV extracted from the infected suckling micebrains. The virus was passed through the cultured cells, until specific CPE were observed (Zheng et al., 2009).

\section{Histopathology of mice brain:}

Infected mice brain was subjected for histopathological examination. Using 10\% formalin after cutting into pieces of about $3 \mathrm{~mm}$ thickness. The tissue sections were placed into glass slides and stained by Haematoxyline and Eosin stain (Bancroft and Gamble, 2002).

\section{Identification of BEFV by (RT- PCR):}

The BEFV RNAs were extracted from the infected cells using Gene JET Viral RNA PurificationKit (Thermo Scientific). The BEFV G gene was amplified using GF primer (5'-ATG TTC AAG GTC CTC ATA ATT ACC-3') and GR primer (5'-TAA TGA TCA AAG AAC CTA TCA TCA C-3'). cDNA was synthesized using GF primer at $42^{\circ} \mathrm{C}$ for $50 \mathrm{~min}$, and then the mixture was heated at $95^{\circ} \mathrm{C}$ for $5 \mathrm{~min}$ to stop the reaction. The obtained cDNA was amplified by the following protocol: initial denaturation at $95^{\circ} \mathrm{C}$ for 5 min, 35 cycles of amplification consisting of $94^{\circ} \mathrm{C}$ for 30 sec denaturation, $52^{\circ} \mathrm{C}$ for $1 \mathrm{~min}$ annealing and $72^{\circ} \mathrm{C}$ for 2 min extension. Finally an extension cycleat $72^{\circ}$ for 10 min (Wang et al., 2001). 


\section{Phylogenetic analysis of the BEFV:}

The amplified PCR fragments of BEFV G gene were purified using QIA quick PCR purification kit (Qiagen, Valencia, CA, USA) and directly sequenced in both orientations. The nucleotide sequences of the BEFV G gene of the Egyptian isolates were compared with other sequences of BEFV isolates obtained from the GenBank database, using the Clustal W program (Thompson et al., 1994). The phylogenetic tree was builtthrough the neighbor-jointing method (Saitou et al., 1987). Evolutionary distances were calculated using the Kimura 2-parameter method (Kimura, 1980). The percentage of replicate trees in which the associated taxa clustered together in the bootstrap test (100 replicates) is listed next to the branches (Felsenstein, 1985). Evolutionary analyses were constructed in MEGA6.6 (Tamura, 2013).

\section{RESULTS}

\section{Virus Isolation:}

BEFV was isolated by intracerebral inoculation of suckling mice and in cultured cells (VERO, MDBK). The infected suckling mice showed convulsions, paralysis of hind limb, abnormal gait and death (Fig. 1A, B). The infected cells either MDBK or VERO cells showed specific CPE in the form of cell rounding, granulation of the cytoplasm, cellular degeneration that end with cellular detachment from the surface of the cell culture flask leaving empty spaces. These stages of cellular changes occur in a period beginning from the 1 st 24 hours post infection and end within 72 hours (Fig. 2). 
Samy Kasem et., al.

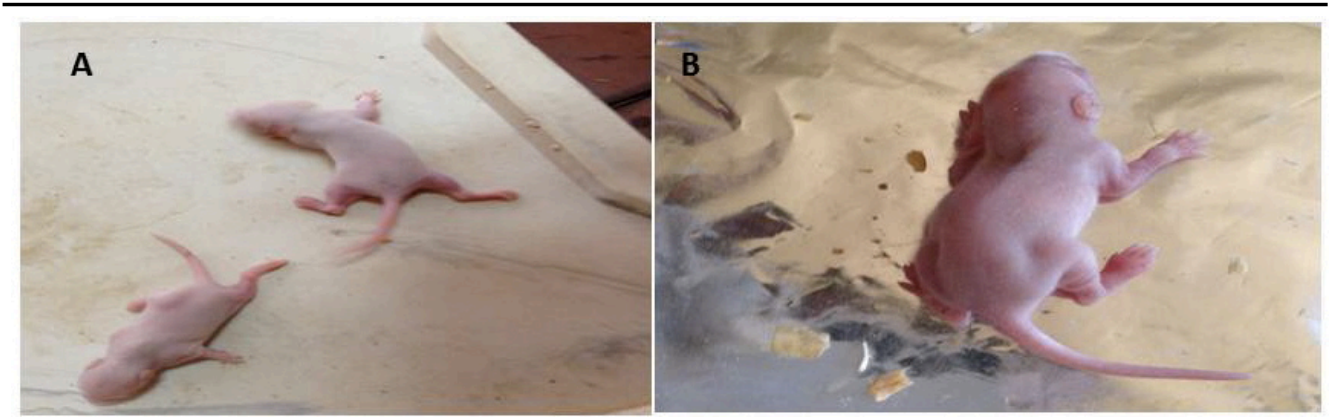

Fig. (1): Paralysis of both hind legs and tail of baby mice inoculated with BEF virus isolate (A). Arched back in baby mice inoculated with BEF virus isolate (B).
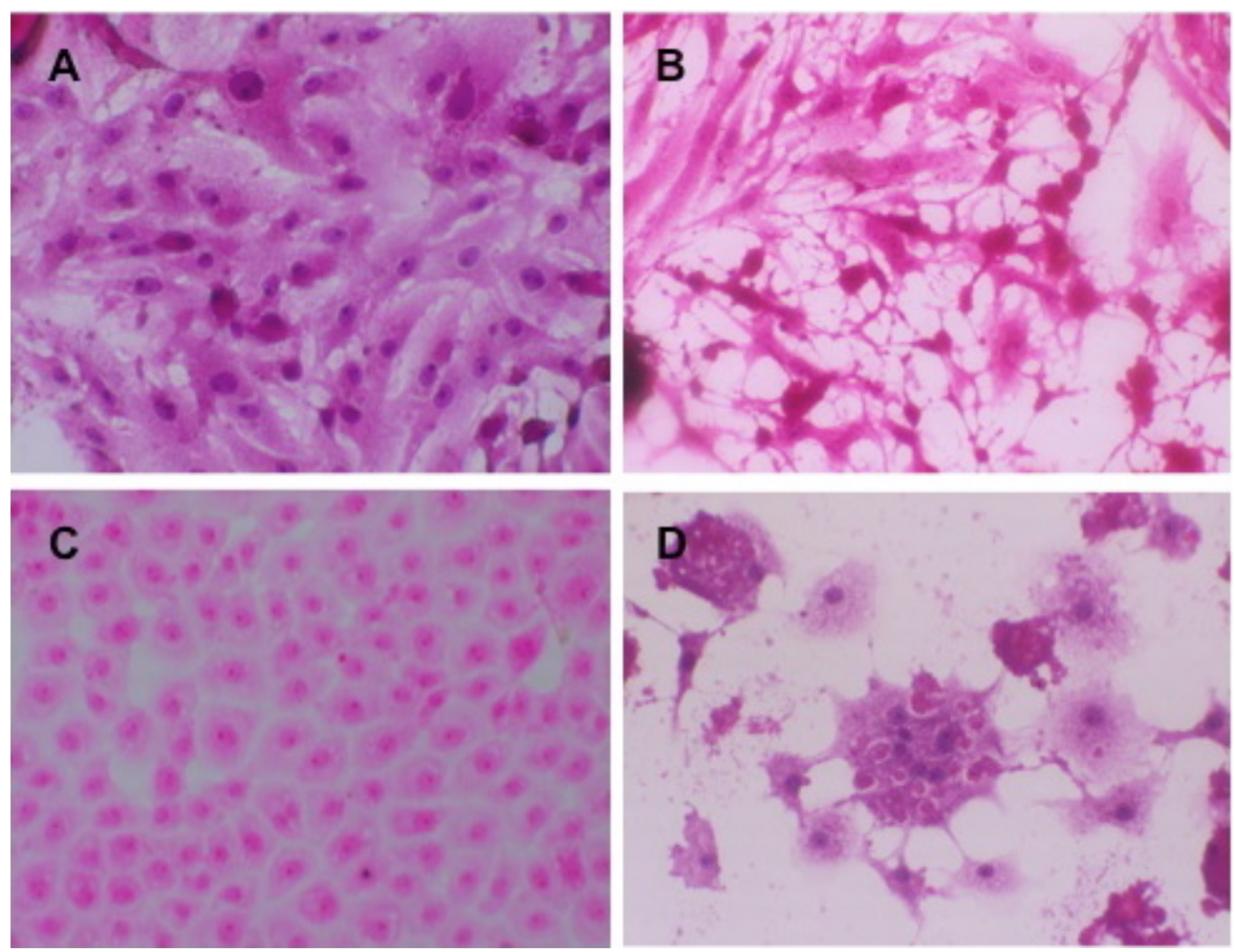

Fig. (2): Normal Vero cells (A) while CPE in Vero cells inoculated with BEF virus (B). Normal MDBK cells (C) and CPE in MDBK cell lines infected with BEFV(D).

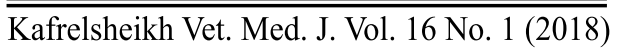


Phylogenetic Analysis Of Bovine Ephemeral Fever ...

\section{Histopathology of mice brain:}

Infected mice showedfatal encephalitis in the form of vacuolation and degeneration of the ependymal cells lining the ventricle of baby mice brain (Fig. 3A), vascular congestion and perivascular edema associated with ischemic neuronal injury in baby mice brain (Fig. 3B), Hyperaemia in cerebral meningeal blood vessels (Fig. 3C) and vasculitis associated with ischemic neuronal degeneration (Fig. 3D).
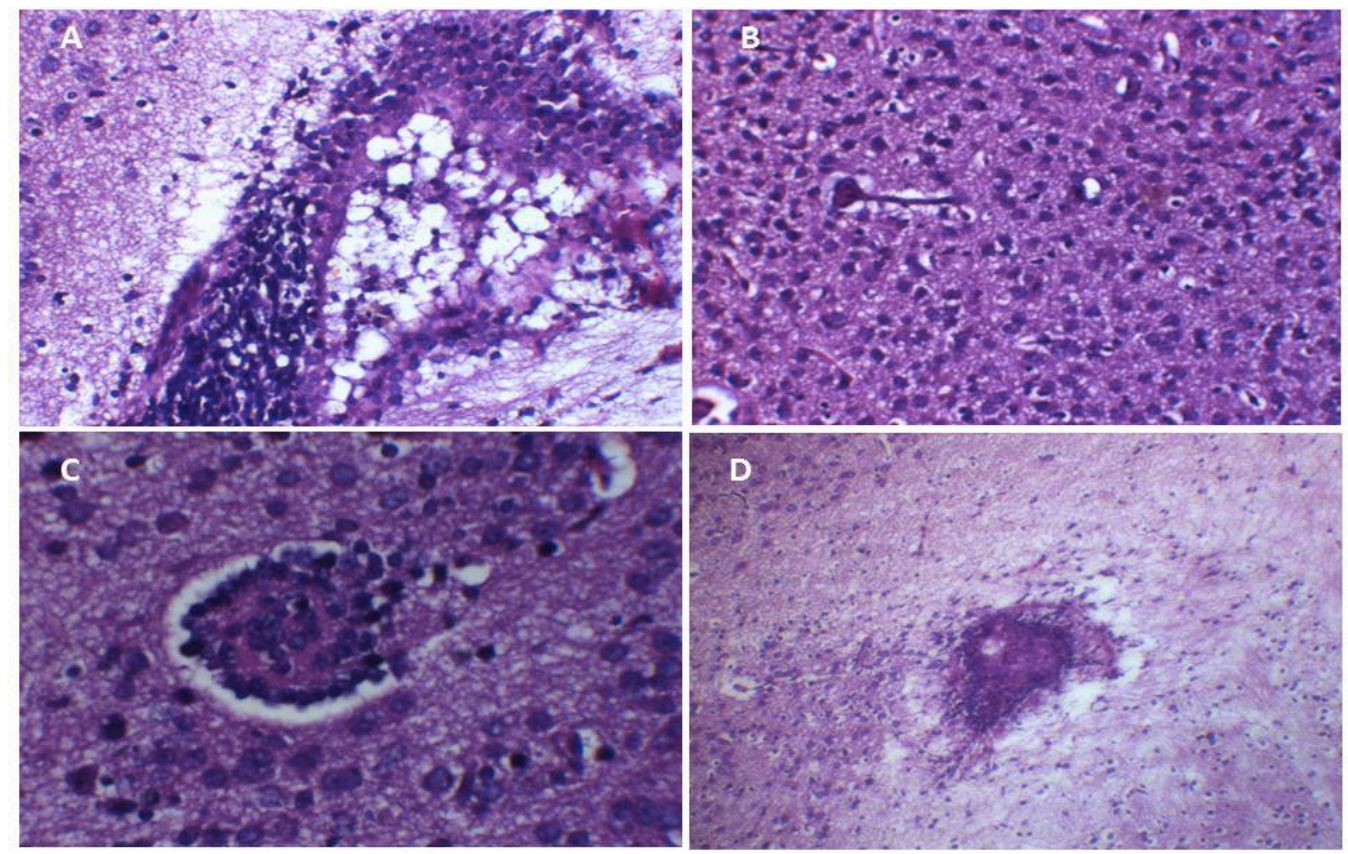

Fig. (3): Infected mice brain show fatal encephalitis. The tissue sections were stained by Haematoxyline and Eosin stain.

\section{Identification of BEFV by RT- PCR:}

BEFV were detected with RT-PCR using specific primers targeting the G gene. The cDNAs were amplified producing a clear single band 1872bp in length on ethidium bromide stained agarose gel (Fig. 4).

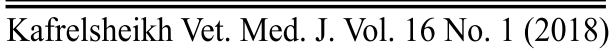


Samy Kasem et., al.

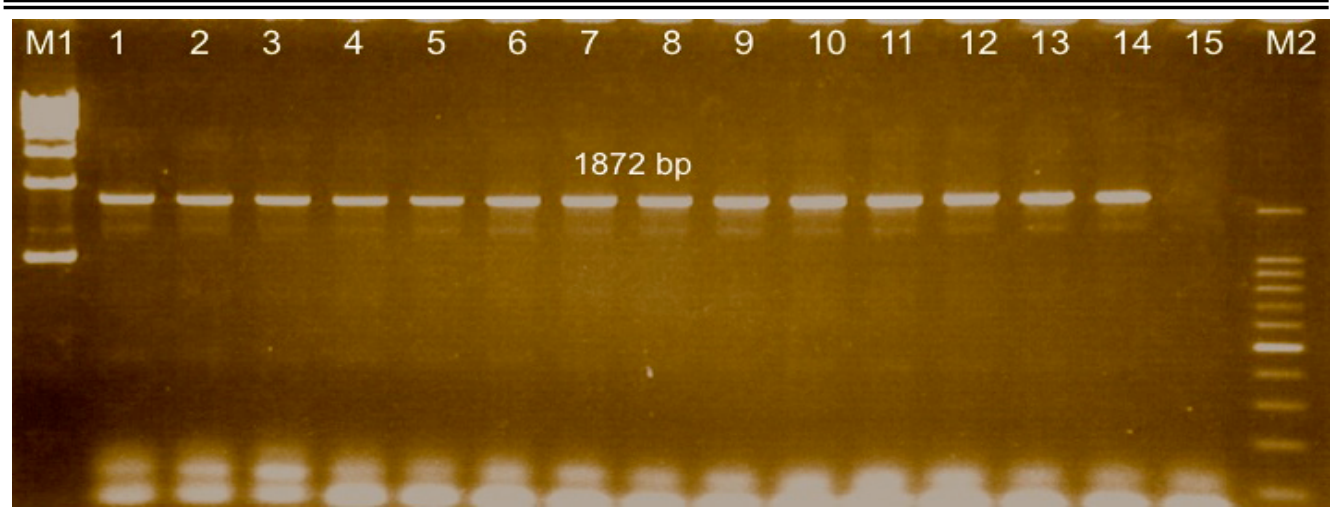

Fig. (4): Agarose gel electrophoresis of PCR product (1872bp) using BEFV glycoprotein G specific primers. Lane M1: DNA ladder molecular weight marker (1500bp); lane 1-13:positive samples, band at 1872bp. 14: control positive, 15: negative control; M2: DNA ladder molecular weight marker (100bp)

\section{Phylogenetic analysis of BEFV:}

The Egyptian BEFV sequences corresponding to the ectodomain region were aligned with BEFV strains isolated from Turkey, Taiwan, Israel, Japan, and Australia. Depending on the nucleotide sequence of the analyzed $G$ genes, the phylogenetic tree was constructed with other BEFV isolates obtained from the Gene Bank database (Fig. 5).

No major differences were detected among the $G$ gene of any isolates as all nucleotide sequences of BEFV $G$ gene were highly conserved among the BEFV isolates obtained from China, Israel, Turkey, Japan, and Taiwan. The identities of the nucleotide sequence of the Egyptian isolate ranged from96\% to Israeli isolates (JN833635.1 ISR10/3, JN833634.1 ISR10/2, JN833632.1 ISR04 Israel, JN833630.1 ISR00 Israel and JN833631.1 ISR01 Israel), 95\% to Turkish isolates, 94\% to Japanese, Taiwanese and Chinese isolates, while the lowest identity 91\% was with the Australian isolates. The identities of the Egyptian isolate to other isolates were shown in (Fig. 5). 


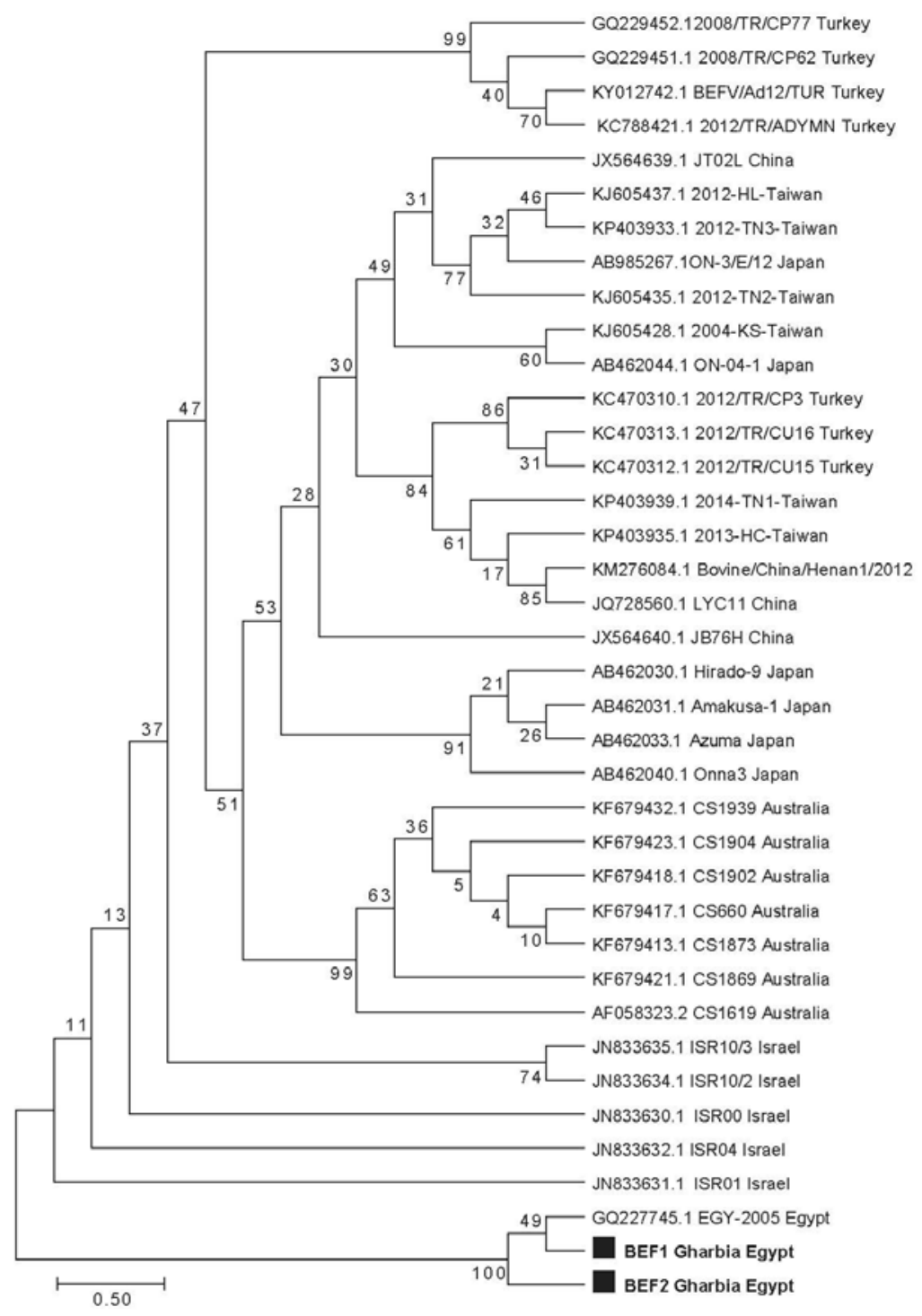

Fig. (5): Phylogenetic relationships of the BEFV isolates based on the comparison of the $\mathrm{G}$ gene sequences. The evolutionary tree was constructed by the neighborjoining method with Kimura two-parameter model distances using the MEGA6.6 program. The branching pattern was evaluated by bootstrap test analysis with 100 replicates. The phylogenetic tree was performed with BEFV reference strains available from GenBank database comparing of the nucleotide sequences of the same gene region of BEF viruses.

$\overline{\text { Kafrelsheikh Vet. Med. J. Vol. } 16 \text { No. } 1 \text { (2018) }}$ 


\section{DISCUSSION}

Bovine ephemeral fever has been recorded in Egypt since 1895, with morbidity reaching $40-50 \%$ during epidemics. Consequently, the disease became of high priority as the development of cattle and buffalo industries. This disease causes direct economic losses, firstly due to animal morbidity and mortality during outbreaks, and secondly because trade in valuable breeding stock is reduced by costly laboratory examination for the detection of diseases. Despite the economic impact of BEF in Egypt, little was known about disease epidemiology, potential for vaccine management and risks.

The presence of this pathogen can be due to lack of vaccination, presence of arthropod vector (mosquitoes) during summer season. In Egypt, Recent outbreaks of the disease were characterized by increaseratesof morbidity and mortality as in summer of 1991, 2000, 2001, 2004, 2010and 2012 (Zaghawa et al., 2000; Kasem, 2004; Kasem et al.,2014). During the last period, dramatic clinical manifestations and server economic losses created substantial awareness either in individual or industry owners about the transmission, epidemiology, anddisease control to overcome the enormous economic losses.

This study aimed to isolate and genetically characterize the causative agent of suspected cases of BEF appeared in Egypt in the period extended from (2013 to 2016). Confirmation of clinical signs by virus isolation and RT-PCR was done. BEFV was isolated either in baby mice showing convulsions, paralysis of hind limb and death of baby mice or in cell cultures as (Vero) and (MDBK) cells. Cytopathic effects were Kafrelsheikh Vet. Med. J. Vol. 16 No. 1 (2018) 
visible on 2-5 days post inoculation including slight rounding of cell followed by destruction of the entire cell sheet within 24-48 hours (Zheng et al., 2009).

So far, the phylogenetic relationships of BEFV isolated from Egypt and those from other countries have not been studied. The phylogenetic relationships of the $G$ gene sequence of BEFV isolated in Australia, Japan, Taiwan, Turkey, Israel and China were previously analyzed (Kato et al., 2009; Zheng et al., 2012; Tonabket al., 2013).

The G gene of the isolated BEFV was successfully amplified by RT-PCRrevealed one specific band at $1872 \mathrm{bp}$, andsequenced in both directions. The evolutionary tree was createdbased on the nucleotide sequences. The study revealed that the recent BEFV Egyptian isolate were closely related with the Israeli isolates (JN833635.1 ISR10/3, JN833634.1 ISR10/2, JN833632.1 ISR04 Israel, JN833630.1 ISR00 Israel and JN833631.1 ISR01 Israel). The results showed that the phylogenetic relationships between the BEFV isolates were closely intertwined with geographical location. The close genetic relationships among BEFV strains can be derived if the isolates originate from neighboring regions. Similarly, BEFV isolates derived from widely separated areas have distant genetic relationships. This may indicate that BEFV circulates in vicinity regions for a long time.

\section{Acknowledgements:}

The Science and Technology Development Fund (STDF), Egypt, Grant No. 4142, financially supported this project. 


\section{REFERENCES}

- Bancroft J. D. and Gamble M. (2002). Theory and practice of histological techniques.5th. Ed. Edinburgh. Churchill Livingstone Pub., pp 172-5, pp 593-620.

- Cybinski D. H.; Walker P. J.; Byrne K. A.; Zakrzewski H. (1990). Mapping of antigenic sites on the bovine ephemeral fever virus glycoprotein using monoclonal antibodies. J Gen Virol 71:2065-2072.

- Dhillon J.; Cowley J. A.; Wang Y. and Walker P. J. (2000). RNA polymerase (L) gene and genome terminal sequences of ephemeroviruses bovine ephemeral fever virus and Adelaide River virus indicate a close relationship to vesiculovirus. Virus Res. 70:87-95.

- Felsenstein J. (1985). Confidence limits on phylogenies: an approach using the bootstrap. Evolution. 39:783-791.

- Hsieh Y. C.; Chen S. H.; Chou C. C.;Hsiao H. W.; Chen S. Z.; Lee Y. F. and Liu H. J. (2005). Bovine ephemeral fever in Taiwan (20012002). J Vet Med Sci. 67:411-416.

- Kasem S. (2004). Seroservillence on Bovine Ephemeral Fever virus in Delta provinces, Master thesis, Department of Virology, Faculty of Veterinary Medicine Kafrelsheikh University, Egypt.

- Kasem S.; Dawod A.; Khodier M.; Kotb A.; Abouelyazeed M.; Abdel Kareem S and Ibrahim B. (2014). Isolation and Characterization of Bovine Ephemeral Fever Virus in Delta Provinces, Egypt 2012. Global Veterinaria13: 972-976. 
- Kato T.; Aizawa, M.; Takayoshi K.; Kokuba, T.; Yanase T.; Shirafuji H.; Tsuda T. and Yamakawa, M. (2009). Phylogenetic relationships of the $\mathrm{G}$ gene sequence of bovine ephemeral fever virus isolated in Japan, Taiwan and Australia. Vet Microbiol 137:217-223.

- Kawther S. Z. and Wahid M. A. (2011). Investigation of Bovine Ephemeral Fever Virus in Egyptian cows and buffaloes with emphasis on isolation and identification of a field strain. Global Veterinaria 5: 447- 425.

- Kimura M. (1980). A simple method for estimating evolutionary rate of base substitutions through comparative studies of nucleotide sequences. J MolEvol 16:111-120.

- Kongsuwan K.; Cybinski D. H.; Cooper J. and Walker P. J. (1998). Location of neutralizing epitopes on the $G$ protein of bovine ephemeral fever rhabdovirus. J Gen Virol 79:2573-2581.

- Rabagliati D. S. (1924). Three days' fever or sickness in cattle. Vet Rec 4: 503-5.

- Saitou N. and Nei M. (1987). The neighbor-joining method: a new method for reconstructing phylogenetic trees. MolBiolEvol 4:406-425.

- St. George T. (1997). Effective treatment of bovine ephemeral fever. Aust Vet J 75: 221-222.

- Tamura K., Stecher, G.; Peterson D.; Filipski A.; and Kumar S. (2013). MEGA6: Molecular Evolutionary Genetics Analysis Version 6.0. Molecular Biology and Evolution 30: 2725-2729. 
- Thompson J. D.; Higgins D. G. and Gibson T. J. (1994). CLUSTAL $\mathrm{W}$ : improving the sensitivity of progressive multiple sequence alignment through sequence weighting, position-specific gap penalties and weight matrix choice. Nucleic Acids Res. 22:4673-4680.

- Tonabk S.; Berber E.; Yoruk M. D.; Azkur A. K.; Pestil Z and Bulut H. (2013). A Large-Scale Outbreak of Bovine Ephemeral Fever in Turkey, 2012. J Vet Med Sci 75: 1511-1514.

- Venter G. J.; Hamblin C. and Paweska J.T. (2003). Determination of the oral susceptibility of South African livestock-associated biting midges, Culicoides species, to bovine ephemeral fever virus. Med Vet Entomol 17: 133-137.

- Walker P. J.; Keren A. B.; Daisy H. C.; Denise L. D. and Doolan Y. W. (1991). Proteins of bovine ephemeral fever virus. J Gen Virol 72:67-74.

- Walker P. J.;Byme K. A.; Riding G. A.; Cowley J. A.; Wang Y. and McWilliam S. M. (1992). The genome of bovine ephemeral fever rhabdovirus contains two related glycoprotein genes. Virology 191:49-61.

- Walker P. J.; Wang Y.; Cowley J. A.; McWilliam S. M. and Prehaud C. $\boldsymbol{J}$. (1994). Structural and antigenic analysis of the nucleoptotein of bovine ephemeral fever rhabdovirus. J Gen Virol 75:1889-1899.

- Walker P. J. (2005). Bovine ephemeral fever in Australia and the world. Currt. Top. MicrobiolImmunol 292:57-80.

- Wang F.; Hsu A. M. and Huang K. J. (2001). Bovine ephemeral fever in Taiwan. J Vet Diagn Invest 13: 462-467. 
- Wunner W. H.; Calisher C. H.; Dietzgen R. G.; Jackson A. O.; Kitajima E. W.; Lafon M.; Leong J. C.; Nichol S.; Peters D.; Smith J. S. and Walker P. J. (1995). Rhabdoviridae. In Virus Taxonomy. Edited by Murphy, F. A., Fauquet, C. M., Bishop, D. H. L., Ghabrial, S. A., Jarvis, A. W., Martelli, G. P., Mayo, M. A. and Summers, M. D. Vienna: Sixth Report of the International Committee on Taxonomy of Viruses. Springer-Verlag: 275-288.

- Yeruham I.; Sharir B.; Yadin H.; Tiomkin D. and Chai D. (2003). Bovine ephemeral fever in beef cattle herds in the Jordan valley. Vet Rec 152: 86-88.

- Zaghawa A.; Okeila M. A.; Khader A. M. and Hassan H. Y. (2000). An outbreak of Bovine Ephemeral Fever in Egypt during 2000: I. Clinical and epidemiological investigations. 9 th Sci. Cong. 19-20 Nov. 2000, Faculty Vet. Med., Assiut Univ., Egypt.

- Zheng F. and Qiu, C. (2012). Phylogenetic relationships of the glycoprotein gene of bovine ephemeral fever virus isolated from mainland China, Taiwan, Japan, Turkey, Israel and Australia. Virol J 9: 268-275.

- Zheng F. Y.; Lin G. Z.; Qiu C. Q.; Zhou J. Z.; Cao X. A. and Gong $X$. W. (2009). Isolation and characterization of a field strain of bovine ephemeral fever virus in China J Anim Vet. Adv 8:1478-1483. 